\title{
Advances in antibiotic therapy in the critically ill
}

\author{
Jean-Louis Vincent ${ }^{1 *}$, Matteo Bassetti ${ }^{2}$, Bruno François ${ }^{3}$, George Karam ${ }^{4}$, Jean Chastre ${ }^{5}$, Antoni Torres ${ }^{6}$, \\ Jason A. Roberts ${ }^{7}$, Fabio S. Taccone ${ }^{1}$, Jordi Rello ${ }^{8}$, Thierry Calandra ${ }^{9}$, Daniel De Backer ${ }^{10}$, Tobias Welte ${ }^{11}$ \\ and Massimo Antonelli ${ }^{12}$
}

\begin{abstract}
Infections occur frequently in critically ill patients and their management can be challenging for various reasons, including delayed diagnosis, difficulties identifying causative microorganisms, and the high prevalence of antibiotic-resistant strains. In this review, we briefly discuss the importance of early infection diagnosis, before considering in more detail some of the key issues related to antibiotic management in these patients, including controversies surrounding use of combination or monotherapy, duration of therapy, and de-escalation. Antibiotic pharmacodynamics and pharmacokinetics, notably volumes of distribution and clearance, can be altered by critical illness and can influence dosing regimens. Dosing decisions in different subgroups of patients, e.g., the obese, are also covered. We also briefly consider ventilator-associated pneumonia and the role of inhaled antibiotics. Finally, we mention antibiotics that are currently being developed and show promise for the future.
\end{abstract}

\section{Background}

Intensive care unit (ICU) patients are particularly likely to have or develop infection, in part because infection is a reason for admission and in part because of immunosuppression associated with critical illness and the large number of invasive devices used in these patients. Correct and adequate antibiotic coverage is essential but can be complex as a result of delayed identification of microorganisms, the impact of critical illness and therapy on pharmacokinetics (PK) and pharmacodynamics (PD) of antibiotics, and the high prevalence of antibiotic-resistant strains.

\footnotetext{
* Correspondence: jlvincent@intensive.org

${ }^{1}$ Department of Intensive Care, Erasme Hospital, Université libre de Bruxelles, 1070 Brussels, Belgium

Full list of author information is available at the end of the article
}

In this review, we briefly highlight the importance of early infection diagnosis before discussing some of the key issues related to antibiotic management, including problems associated with timing, duration, and dosing. We also briefly consider ventilator-associated pneumonia (VAP), the use of inhaled antibiotics, and new antibiotic and adjunct strategies for the future. We focus on bacterial infections and issues associated with multi-drug resistance will not be covered.

\section{Diagnosis}

The diagnosis of infection in critically ill patients and identification of causative microorganisms and their antibiotic susceptibilities can be a challenge and yet early, appropriate antibiotic therapy is associated with improved outcomes [1], so accurate, rapid diagnosis is important. Typical clinical signs of infection, such as fever or raised white blood cell count, are non-specific and can occur in many other conditions in the critically ill population. Similarly, although many biomarkers, e.g., C-reactive protein and procalcitonin (PCT) to name just two [2], have been suggested to help diagnosis or to rule out infection, none is specific for infection and all can be altered in other conditions that commonly affect ICU patients. Diagnosis of infection still relies largely on culture-based techniques, which can take several days for a positive result to be available. Moreover, in patients already receiving antibiotics, cultures may be negative.

In response to this problem, more rapid microbiological identification methods are being developed, including polymerase chain reaction (PCR) and mass spectrometry with or without electrospray ionization [3-6]. These tests, particularly when associated with an antimicrobial therapy team or pharmacist trained in infectious diseases, may result in shorter times to effective therapy, shorter lengths of hospital stay, and reduced hospital costs $[3,4]$ and are likely to become more widely used in the near future [7]. 


\section{Antibiotic therapy}

\section{Empiric treatment}

It is generally accepted that antibiotics should be administered as soon as possible once infection is identified [8], although randomized data to support this notion are lacking in humans for obvious ethical reasons, and most data are from observational studies.

There has been and still is considerable debate regarding the potential benefits of combination versus monotherapy in the empiric management of infection in critically ill patients. Combination therapy has advantages and disadvantages (Table 1). A first potential advantage is in vitro synergy between two drugs resulting in improved bacterial killing. For example, a colistinglycopeptide (vancomycin or teicoplanin) combination was shown in vitro to be synergistic against multidrugresistant (MDR) Gram-negative bacteria, especially Acinetobacter baumannii $[9,10]$. Nevertheless, clinical studies have been unable to demonstrate an effect of synergy on outcomes [11, 12], calling into question the importance of synergy with the potent antibacterial agents used as monotherapy today. Another potential advantage is that combination regimens may provide a greater overall spectrum of activity.

One of the most important potential disadvantages of combination therapy is increased drug toxicity, particularly when aminoglycosides are used [13]. Although this increased risk may be acceptable in a critically ill population with a high risk of MDR organisms, it is likely less acceptable in more stable patient populations or where the risk of $\beta$-lactam resistance is lower. Risk of superinfection with resistant bacteria or fungal infections represents another potential disadvantage [14]. Another frequently cited disadvantage of combination therapy is increased cost. However, although drug costs will almost certainly be higher with combination therapy, this increased cost may be acceptable if compensated for by shorter hospital stays and improved patient outcomes.

In a cohort of patients with septic shock, combination therapy of a $\beta$-lactam with other antibiotics was associated with a decrease in 28-day mortality compared with $\beta$-lactam monotherapy [15]. And, in a prospective, multicenter European observational study, combination therapy

Table 1 Some potential advantages and disadvantages of using combination empiric therapy versus monotherapy

\begin{tabular}{ll}
\hline Advantages & Disadvantages \\
\hline $\begin{array}{l}\text { Broader coverage that includes } \\
\text { non-susceptible strains }\end{array}$ & Possible antagonism \\
Anti-bacterial synergy & Possible superinfection \\
Prevents emergence of resistance & May increase resistance \\
& Increased toxicity \\
& Increased costs \\
\hline
\end{tabular}

with macrolides was associated with better outcomes compared with monotherapy in mechanically ventilated patients with community-acquired pneumonia (CAP) [16]. However, not all studies have demonstrated an advantage of combined therapy over monotherapy [17-20]. Importantly, all these studies have compared different antibiotic regimens in different patient populations, making it difficult to generalize the results. In addition, severity of illness can play an important role when comparing mono- and combination therapy. In a meta-regression analysis, Kumar et al. [21] reported that although there was no overall mortality/clinical response benefit with combination therapy for the 50 studies included, when studies were stratified according to baseline mortality risk, combination therapy was consistently associated with benefit in the more severely ill patients. Moreover, the benefits of antibiotic therapy, whether combined or monotherapy, are related to the activity of the chosen antibiotics against the infecting organisms and adequacy has rarely been assessed in these studies.

In current guidelines, combination therapy is suggested for neutropenic patients with sepsis, patients with infections caused by MDR pathogens and patients with severe respiratory infections and septic shock $[8,22]$. In general, decisions regarding the use of combination or monotherapy should be made on an individual basis according to the severity of the disease, likely causative microorganism(s), concomitant diseases, and local microbiological and resistance patterns.

\section{De-escalation?}

Decisions regarding empiric antibiotic therapy are based on two approaches: (1) a judgment that the likely agent has "normal antibiotic susceptibility" and can therefore be treated as such with possible need for "escalation" to second-line drugs after microbiological identification; (2) a judgment, based on local microbiology patterns and clinical presentation, that the infecting microorganism may be MDR and should be treated as such, with possible "de-escalation" to a simpler antibiotic regimen after identification and antibiotic susceptibilities of the causative microorganism are known. More frequently the latter approach is used in the ICU to ensure that all possible causative organisms are initially covered. Indeed, only about $30 \%$ of all antibiotics are used for definitive therapy in which the susceptibility patterns for the infection-associated pathogen are known [23, 24]. In many ICUs, more than $50 \%$ of isolates are resistant to at least one antibiotic [25], and broad-spectrum combination empiric therapy may be warranted in these units to ensure that these organisms are adequately covered. Once susceptibilities are confirmed, the spectrum can be reduced (de-escalated) accordingly, although one 
study reported that de-escalation may actually be feasible in $<50 \%$ of cases [26].

Studies have reported conflicting effects on outcomes with de-escalation in various groups of critically ill patients [27-29]. A systematic review of 493 studies concluded that there was not sufficient evidence to determine whether de-escalation of antibiotic agents was effective and safe for adults with sepsis [30]. Nevertheless, within a context of a dedicated "antibiotic stewardship" program, de-escalation should be encouraged, whenever possible, to optimize antibiotic use [31,32].

\section{When to stop?}

Longer antibiotic courses are associated with MDR pathogen selection and spread, increased risks of toxicity, and higher costs, but courses that are too short risk inadequate bacterial eradication and relapse. Current guidelines advise a 7-10 day course, unless poor prognosis predictors are present (e.g., initial clinical failure, undrainable foci of infection) [8]. Infections caused by Staphylococcus aureus or Pseudomonas aeruginosa may warrant more prolonged antibiotic courses to avoid treatment failures, early relapses or metastatic complications. CAP, with the exception of Legionella pneumonia, should not be treated for more than 8 days in responding patients and invasive abdominal infections may be successfully managed with a 7 -day course $[22,33]$ or even a 4-day course when the source is controlled [34]. A systematic review of 24 studies that compared a shorter (5-7 day) regimen versus a longer (7-21 day) antibiotic course for critically ill patients with various infections identified no differences in terms of clinical cure, microbiological eradication, or survival [35]. Decisions about duration of antibiotic therapy need to be individualized, taking into account different variables regarding the patient (e.g., severity of illness, clinical response), the type of infection (e.g., source control, deepseated infection [e.g., bone infection], MDR pathogens) and the availability of diagnostic tools (e.g., clinical/ laboratory scores, biomarker). An 8-day course will likely be more than sufficient in most ICU patients, and shorter courses may be considered when the source is controlled.

Biomarkers may assist in decisions regarding when to stop antibiotics. Concentrations of PCT, a 116 amino acid peptide, increase during infection and sepsis in correlation with the degree of inflammatory response and the severity of the disease. However, PCT concentrations also increase in some non-septic conditions [36] and remain low in some microbiologically proven bacterial infections, especially when the infectious process remains localized. Nevertheless, PCT concentrations decline quickly when infection is controlled, so that its kinetics during the course of the disease may facilitate decisions to discontinue antibiotics. There is no clear
PCT cutoff value to decide when to stop antibiotics, although high values $(>1 \mathrm{ng} / \mathrm{mL})$ are strongly suggestive of active bacterial infection. A value $<0.5 \mathrm{ng} / \mathrm{mL}$ or a decrease $>80 \%$ from the initial value may be used as a threshold value to stop antibiotics in stable patients. This approach has been evaluated in several randomized controlled trials (RCTs) [37-40]. In the PRORATA trial [40], which included $621 \mathrm{ICU}$ patients half of whom had septic shock, patients in whom antibiotics were started or stopped according to PCT concentrations had significantly more days without antibiotics than controls (14.3 versus 11.6, $p<0.001$ ), without apparent harm.

\section{Dosing issues}

\section{Pharmacokinetics/pharmacodynamics}

Various PK factors are altered in critically ill patients and can have profound effects on the attainment of adequate antibiotic doses:

Target site penetration Because most infection occurs in tissue interstitial fluid, the antibiotic concentration measured in the plasma is actually often only a surrogate for the true concentration at the site of infection and may over- or underestimate the actual interstitial fluid concentration. In critically ill patients, microvascular failure may impair target site penetration [41].

Clearance Several variables can affect the renal clearance of hydrophilic antibiotics. In the setting of hypoalbuminemia, there is enhanced clearance of highly protein-bound drugs. For patients with high cardiac output and low systemic vascular resistance, as in sepsis, renal clearance of drugs may be augmented by increased renal perfusion, to as much as triple the normal rate [42-44], and may be associated with treatment failure despite the patient being susceptible to the antibiotic.

Volume of distribution Multiple factors have been shown to increase the volume of distribution (Vd) of antibiotics beyond the traditionally accepted fluid extravasation that impacts hydrophilic antibiotics. These include an increase in $\mathrm{Vd}$ associated with fluid resuscitation or the physiologic derangements occurring with increased severity of illness [45].

Recently, an enhanced understanding of the PK of antibiotics has developed, largely based on the hydrophilicity of the agents [46]. With hydrophilic agents (e.g., $\beta$-lactam antibiotics, aminoglycosides, glycopeptides, lipopeptides), tissue distribution is limited to the extracellular space, and clearance is predominantly via renal mechanisms. By contrast, with lipophilic agents (e.g., fluoroquinolones, glycylcyclines, lincosamides, macrolides, metronidazole, streptogramins, tetracyclines) tissue distribution includes intracellular penetration and 
hepatic clearance is more common. These variables become important in septic patients because hydrophilic antibiotics require an increased loading dose in the setting of sepsis to ensure therapeutic concentrations are achieved early. With lipophilic agents, an increased loading dose in septic patients is not needed and dose adjustment of these antibiotics is generally only required in the setting of severe hepatic failure [46].

The bacterial killing characteristics of antibiotics are mostly characterized in terms of time-dependent and concentration-dependent killing [47]. With timedependent antibiotics, such as $\beta$-lactams and glycopeptides, maximum bacterial killing occurs when the drug concentration persistently exceeds the minimum inhibitory concentration (MIC) of the pathogen. By contrast, with concentration-dependent antibiotics, such as aminoglycosides and fluoroquinolones, maximum bacterial killing occurs when the peak drug concentration exceeds several times $(>8-10)$ the MIC.

In a prospective multinational point-prevalence study of 361 evaluable patients in which 248 patients were treated for infection, $16 \%$ did not achieve target-free antibiotic concentrations above the MIC. Of these patients, $32 \%$ were less likely to have a positive clinical outcome [48]. These data provide an important glimpse into the relevance of $\mathrm{PK} / \mathrm{PD}$ issues in the management of critically ill patients, and they challenge healthcare providers managing patients in the ICU setting to move away from the "one dose fits all" strategy that has been traditionally employed in clinical medicine and toward a more personalized antibiotic dosing that is individualized to the physiology of the patient being treated [45]. Importantly too, these changes are unpredictable and measurement of drug concentrations will increasingly be employed to ensure doses are adequate.

\section{Doses of $\beta$-lactams}

$\beta$-Lactams are time-dependent antibiotics. Several studies have shown that $\beta$-lactam concentrations are inadequate in patients with sepsis compared with non-critically ill patients when standard dosage regimens are administered, particularly when dealing with difficult-to-treat strains such as $P$. aeruginosa $[49,50]$. To improve PD target attainment, $\beta$-lactams can be administered at increased doses, increased frequency, or by an extended or continuous infusion. Among these options, continuous infusions are often used in critically ill patients and have repeatedly been shown to achieve higher steady-state $\beta$-lactam concentrations compared with trough concentrations with standard intermittent regimens [51], although outcome benefits have not been clearly demonstrated [52]. Interestingly, even when given by continuous infusion, $\beta$-lactam concentrations can still remain below the MIC for difficult-to-treat pathogens, especially in patients with a high creatinine clearance associated with high renal drug elimination [53]. Importantly, $\beta$-lactams have been associated with neurotoxicity and high $\beta$-lactam concentrations may be implicated in clinical neurological deterioration [54]. It is important, therefore, to ensure that concentrations remain within therapeutic ranges.

\section{Doses of aminoglycosides}

To be active, aminoglycosides need to reach peak concentrations at least eight times higher than the MIC for the strain, while low trough concentrations need to be achieved (high concentrations are associated with toxicity). Due to changes in Vd and renal clearance, the PK of aminoglycosides may be altered in sepsis, especially in septic shock, leading to insufficient peak concentrations. Accordingly, aminoglycoside doses have been revisited. For example, the recommended loading dose of amikacin has been increased from 15 to $25 \mathrm{mg} / \mathrm{kg}$ and even these doses may not be high enough in some patients. In a multicenter trial in 80 patients, administration of $25 \mathrm{mg} / \mathrm{kg}$ of amikacin allowed adequate peak concentrations to be achieved in only $70 \%$ of patients [55]. Similar results were observed in a trial of 146 patients [56] in which the higher the fluid balance the lower the chances of reaching adequate concentrations, highlighting the crucial role of changes in aminoglycoside Vd. Importantly, toxic trough concentrations were uncommon in both trials.

When very high peak concentrations need to be reached, as in patients with MDR pathogens with intermediate susceptibility to aminoglycosides, combination of very high doses of aminoglycosides associated with highflow $(50 \mathrm{ml} / \mathrm{kg} / \mathrm{min}$ ) continuous veno-venous hemofiltration may help achieve adequate peak concentrations while minimizing toxicity and, even more importantly, enable daily administration of the agent (and thus more frequent exposure to its bactericidal effects) [57].

\section{Dosing in obese patients}

Obesity is associated with different physiological distributions of protein and water-based tissue (e.g., muscle) and lipid-based tissue (e.g., fat) than are present in nonobese patients. These patients tend to also have a higher blood volume and cardiac output than their non-obese counterparts and are believed to have reduced perfusion of peripheral tissues. These factors can lead to changes in $\mathrm{Vd}$ and drug clearance that necessitate different drug doses to achieve the same concentrations observed in non-obese patients.

Various metrics have been used to help describe drug behavior in obese patients. In general, for antibiotics primarily eliminated by the kidneys, an accurate description of glomerular filtration rate or creatinine clearance is sufficient for predicting drug clearance in obesity. 
Many equations, such as the Cockroft-Gault and Modified Diet in Renal Disease equations, do not perform particularly well at extremes of body weight, in which case less common equations, such as the SalazarCorcoran equation [58], should be substituted where measured urinary collection is not possible.

For aminoglycosides, adjusted body weight is considered the best descriptor of $\mathrm{Vd}$, with clearance varying to a similar extent such that half-life is often the same in obese and non-obese patients [59]. For glycopeptides, total body weight (TBW) is the most accurate descriptor of $\mathrm{Vd}$ and clearance changes [60]. For $\beta$-lactams, there is a lack of consensus amongst the sparse papers, but lean body weight (LBW) is a plausible descriptor for changes in Vd and drug clearance is well described by creatinine clearance [61]. For fluoroquinolones, the data are not completely clear, but LBW seems an appropriate descriptor of changes in $\mathrm{Vd}$ for levofloxacin and either LBW or TBW appear appropriate for ciprofloxacin [62]. For linezolid, there are insufficient data to make strong recommendations for altered dosing in obesity, although differences in PK are considered likely. For daptomycin, TBW has been correlated with changes in Vd and drug clearance [63].

\section{Dosing during extracorporeal therapies}

Renal replacement therapy (RRT) can be delivered by diffusion (hemodialysis), convection (hemofiltration), or a combination of both (hemodiafiltration). It may be delivered continuously (CRRT) or intermittently. There are several papers on drug dosing during CRRT, but very few in critically ill patients receiving intermittent RRT [64]. A specific issue for intermittent RRT is the inconsistent drug clearance likely to occur during a 24-hour period [65]. Such inconsistent clearance is highly problematic for time-dependent antibiotics where unadjusted dosing in the presence of high drug clearance that alternates with no drug clearance will result in potentially very low and very high concentrations over the course of the day exposing the patient to risks of clinical failure and toxicity.

Drugs that are hydrophilic and usually subject to renal clearance are commonly cleared by dialysis [66]. Large molecules $(>1000 \mathrm{Da})$, like vancomycin, are poorly cleared by hemodialysis, although the availability of high-flux filters has increased the clearance of these drugs somewhat. Smaller molecules, like the $\beta$-lactam and aminoglycoside antibiotics, are largely cleared by hemodialysis [66], although this clearance is typically lower than with normal renal function. Protein binding has important effects on drug clearance with highly protein-bound drugs, like teicoplanin, oxacillin and ceftriaxone, having low dialysis clearance because the protein-bound fraction cannot be cleared [66]. Finally, for antibiotics with a larger $\mathrm{Vd}$ there is typically less antibiotic in the vascular compartment and so less is available for clearance. This is seen with the quinolones, which have a comparatively larger $\mathrm{Vd}$ than the $\beta$-lactams or aminoglycosides.

In the absence of clinical PK and dosing data for hemodialysis in critically ill patients, valuable mechanistic insights can be gained from in vitro RRT models. Such experiments have shown that dialysate flow rate is the most important factor associated with hemodialysis clearance of drugs [67]. More data are needed to improve dosing in hemodialysis as the sub-optimal achievement of target concentrations seen in the early phase of therapy in critically ill patients receiving CRRT is likely to also be problematic with intermittent techniques [68].

Antibiotics are commonly required during extracorporeal membrane oxygenation (ECMO); however, few data are available regarding antibiotic PK during ECMO. The major changes in ECMO are increased $\mathrm{Vd}$ and decreased drug clearance, although the extent of such changes remains poorly characterized [69]. Antibiotic concentrations may be further altered during ECMO because of the circuit itself (with associated drug sequestration) and/or the associated systemic inflammation (with vasodilation and capillary leak) [70].

The $\mathrm{Vd}$ and clearance of meropenem, piperacillin and vancomycin seem to be similar in adult patients undergoing ECMO and in controls [71], suggesting that ECMO may not greatly influence antibiotic PK.

\section{A special situation: VAP}

Although its incidence varies widely according to the population and the criteria used [72], VAP is the leading cause of nosocomial infection in the ICU and a risk factor for increased mortality.

\section{Diagnosis of VAP}

Diagnosis of VAP is still a difficult clinical issue with two basic diagnostic strategies [73]: clinical and microbiological (Fig. 1). A recent Cochrane review of five randomized studies [74] found no differences in any of the clinical outcomes between these strategies, although an earlier meta-analysis reported that invasive testing was associated with more antibiotic modifications [75]. A recent study [76] proposed that a modified Clinical Pulmonary Infection Score (CPIS), which included lung echography and serum PCT concentrations, would add sensitivity and specificity to the classic CPIS, but this requires further validation. Rapid PCR techniques may help increase the sensitivity and specificity of the clinical suspicion of VAP.

\section{Should we consider preemptive therapy in VAP?}

Respiratory tract colonization precedes VAP in nearly $100 \%$ of cases. Risk factors include prior antibiotics, outof-hospital intubation, presence of tracheal intubation 

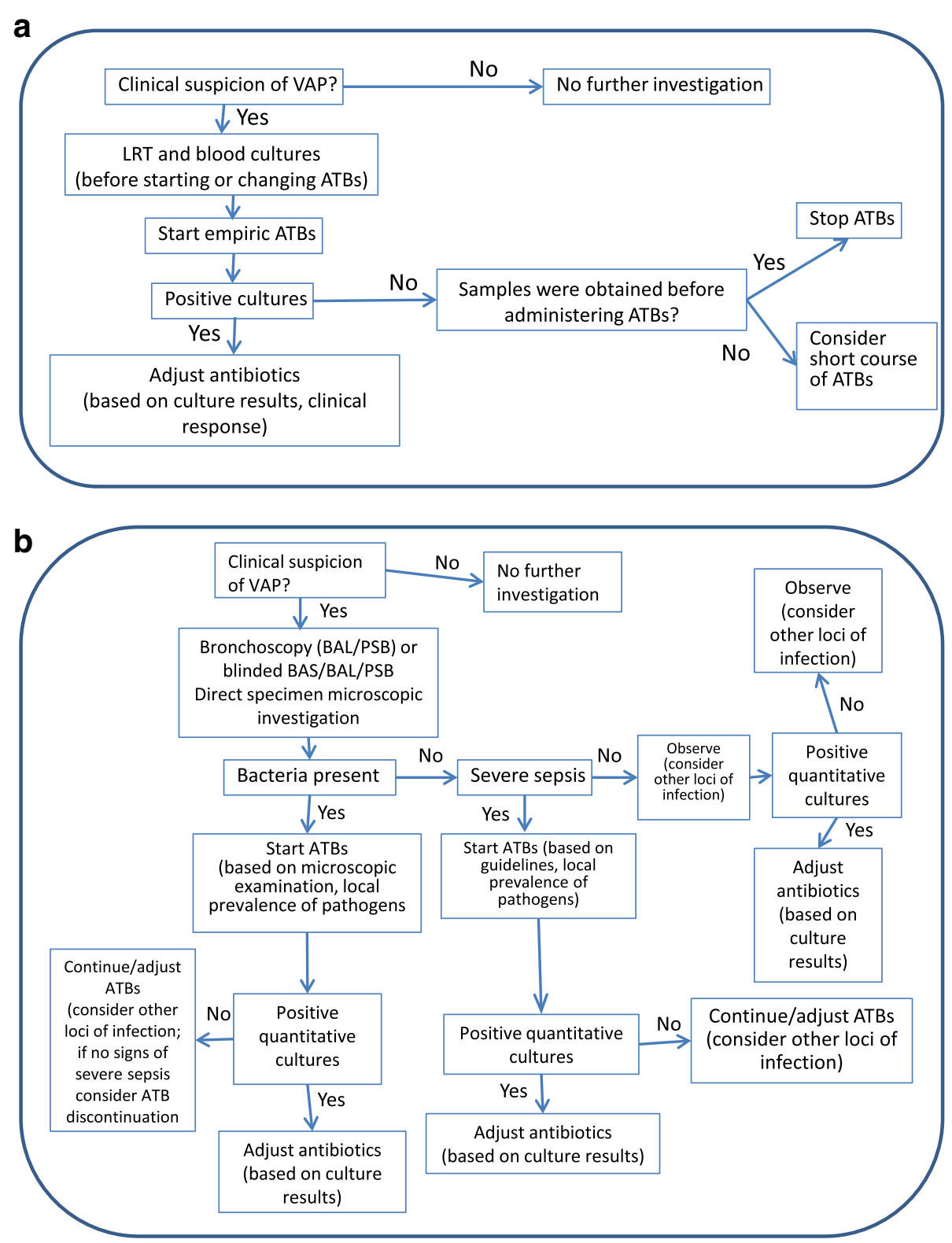

Fig. 1 Clinical (a) and microbiological (b) strategies for diagnosis and management of ventilator-associated pneumonia (VAP). ATB antibiotic, BAL bronchoalveolar lavage, BAS bronchial aspirate, LRT lower respiratory tract, PSB protected specimen brush. Modified from [116] with permission

devices, and duration of intubation. Bacterial biofilm formation on the endotracheal tube may play a key role in colonization. Hospitalized patients tend to become colonized with organisms in the hospital environment within 48 hours. Thus, VAP pathogenesis could be considered as a continuum from ICU admission to confirmed pneumonia through colonization and invasion depending on virulence factors.

Very few trials have tested use of preemptive antibiotics in VAP. Several studies have shown reduced rates of VAP development in patients with ventilator-associated tracheobronchitis (VAT) who received appropriate antibiotic therapy [77-79]. VAT is believed-although this remains controversial - to be an intermediate process between colonization and VAP. In post-cardiac surgery patients at risk of VAT/VAP, Bouza et al. [80] reported a reduction in the VAT/VAP rate in patients who received a 3-day preemptive course of linezolid and meropenem compared with those who did not, but this approach was associated with development of linezolid resistance. In another study, a single dose of ceftriaxone, ertapenem, or levofloxacin within $4 \mathrm{~h}$ of endotracheal intubation in 
comatose patients was associated with reduced earlyonset VAP with no increased incidence of infection by multiresistant microorganisms [81]. Clearly further research is needed before any recommendations can be made regarding the use of pre-emptive therapy in VAP.

\section{A place for nebulized antibiotics in VAP?}

For patients receiving mechanical ventilation, aerosolized antibiotics delivered via an efficient system may achieve airway-drug concentrations 100-300-fold higher than the MIC of most bacteria, including MDR pathogens, with reduced systemic toxicity and reduced pressure for selection of resistant organisms [82-84]. In a double-blind, placebo-controlled study in 42 ICU patients requiring prolonged mechanical ventilation who were colonized and/or infected with potentially difficult-to-treat pathogens (e.g., methicillin-resistant S. aureus [MRSA] and non-fermenting Gram-negative bacteria), aerosolized antibiotics successfully eradicated the existing MDR organisms and reduced the pressure for new resistance [85].

However, various technical issues need to be addressed. During mechanical ventilation, large droplets $(>5 \mu \mathrm{m})$ are more likely to be trapped in the circuit, whereas smaller particles $(<0.5 \mu \mathrm{m})$ are more likely to be expulsed during expiration, so that the size of the particles generated should optimally be between 1 and $3 \mu \mathrm{m}$. Particle size depends on the aerosol generator and ventilator settings. On ultrasonic nebulizers, aerosol particle size is inversely proportional to the piezoelectric crystal vibration frequency, and drug output is directly proportional to the amplitude of crystal vibration. On vibrating mesh nebulizers, droplet size is more homogeneous and easier to calibrate [86]. To increase lung deposition, tidal volume has to be set at $500 \mathrm{~mL}$ (or more) in adults, with a long inspiratory time (which can be obtained by increasing the I:E ratio) and reduced inspiratory flow. When using a heat/moisture exchanger, it has to be removed during nebulization (and replaced at the end of the aerosol treatment). When using a heated humidifier, it should be switched off during nebulization or the amount of drug should be increased [87].

Several antibiotics have been studied as aerosolized agents; however, how their dosing should be adjusted for optimal efficacy and safety remains unclear. Studies suggest that nebulized aminoglycosides are superior to intravenous administration for providing high tissue concentrations and inducing rapid and potent bacterial killing $[88,89]$, but renal toxicity may be a concern. In 40 patients with VAP randomized to nebulized or intravenous amikacin and ceftazidime, acquisition of pertreatment antibiotic resistance occurred only in the intravenous group [90]. In a meta-analysis of 12 studies, nebulized antibiotics were associated with improved clinical cure rates in VAP, although this effect did not persist after trial sequential analysis and there was no effect on microbiological cure, lengths of stay, or mortality [91].

In recent years, there has been interest in the use of inhaled colistin (in the form of colistimethate sodium) in VAP because of its known activity against MDR Gram-negative bacteria and the poor penetration of the intravenous form in the lungs [92]. Studies on aerosolized colistimethate as an adjunct to intravenous colistimethate for treating VAP yielded conflicting results [93-96]. A recent meta-analysis of studies suggested that addition of aerosolized colistin in VAP was associated with improved clinical and microbiological response rates but had no effect on mortality [97], but the quality of the evidence was poor.

\section{New antibiotics in the pipeline}

Very few new antibiotics have been developed over the past 10 years but there are some promising agents in the pipeline (Table 2) [98]. Solithromycin, a new macrolide (fluorketolide), effectively kills macrolide-susceptible pathogens, like Streptococcus pneumoniae, Haemophilus influenzae, and atypical pathogens, and is also effective against macrolide-resistant bacteria. Solithromycin resistance has not yet been identified. In a phase II study in 132 patients with moderate to severe CAP, clinical and microbiological success rates were similar in patients treated with solithromycin (800 $\mathrm{mg}$ on day $1,400 \mathrm{mg}$ from day 2) or levofloxacin (750 mg daily) [99]. Adverse effects, especially diarrhea, were significantly more frequent with levofloxacin (45.6 versus $29.7 \%$ ).

Omadacycline (an aminomethylcycline) and eravacycline (a fluorocycline) are developed from the tetracyclines and have now entered phase II clinical trials. Omadacycline is available for intravenous and oral therapy. It is effective against a large number of sensitive but also resistant Gram-positive pathogens (including vancomycin-resistant enterococci and MRSA) and against some Gram-positive pathogens, such as $H$. influenzae, Klebsiella, and Escherichia coli [100]. Eravacycline is also active against resistant Gram-negative pathogens but not against $P$. aeruginosa or Burkholderia.

Fifth-generation cephalosporins with MRSA activity (ceftaroline, which does not have Pseudomonas activity, and the Pseudomonas-active ceftobiprole) are available in a number of countries, but have not been used extensively (because of a lack of data) in critically ill patients. In a recent RCT, ceftobiprole $(3 \times 500 \mathrm{mg})$ was compared with the combination of ceftazidime $(3 \times 2 \mathrm{~g})$ and linezolid $(2 \times 600 \mathrm{mg})$ in 781 patients with nosocomial pneumonia, including 210 with VAP [101]. Clinical cure rates overall were around $50 \%$ in both groups, but ceftobiprole performed less well in VAP (23.1 versus $36.8 \%$ cure rate). Ceftolozane/tazobactam is a new cephalosporin that differs from ceftazidime by a modification 
Table 2 The most important new antibiotic agents in the pipeline

\begin{tabular}{|c|c|c|c|}
\hline Drug class & Drug name & $\begin{array}{l}\text { Development } \\
\text { phase }\end{array}$ & Potential indications \\
\hline Cephalosporin & GSK-2696266 & Phase 1 & Bacterial infections \\
\hline \multirow[t]{3}{*}{$\begin{array}{l}\text { Novel cephalosporin + } \\
\beta \text {-lactamase inhibitor }\end{array}$} & Ceftolozane + tazobactam & $\begin{array}{l}\text { Approved } \\
\text { March } 2015\end{array}$ & $\begin{array}{l}\text { Complicated urinary tract infections, complicated intra-abdominal } \\
\text { infections, acute pyelonephritis (kidney infection), hospital-acquired } \\
\text { bacterial pneumonia/ventilator associated pneumonia }\end{array}$ \\
\hline & Ceftaroline + avibactam & Phase 2 & Complicated urinary tract infections \\
\hline & $\begin{array}{l}\text { Ceftazidime + avibactam } \\
\text { (CAZ-AVI) }\end{array}$ & Approved 2015 & $\begin{array}{l}\text { Complicated urinary tract infections, complicated intra-abdominal } \\
\text { infections, acute pyelonephritis (kidney infection), hospital-acquired } \\
\text { bacterial pneumonia/ventilator-associated bacterial pneumonia }\end{array}$ \\
\hline $\begin{array}{l}\text { Monobactam + novel } \\
\beta \text {-lactamase inhibitor }\end{array}$ & $\begin{array}{l}\text { Aztreonam + avibactam } \\
\text { (ATM-AVI) }\end{array}$ & Phase 1 & Bacterial infections \\
\hline \multirow[t]{2}{*}{$\begin{array}{l}\text { Carbapenem }+ \text { novel } \\
\beta \text {-lactamase inhibitor }\end{array}$} & Carbavance & Phase 1 & $\begin{array}{l}\text { Complicated urinary tract infections, complicated intra-abdominal } \\
\text { infections, hospital-acquired bacterial pneumonia/ventilator-associated } \\
\text { bacterial pneumonia, febrile neutropenia }\end{array}$ \\
\hline & MK-7655 + imipenem/cilastatin & Phase 2 & $\begin{array}{l}\text { Complicated urinary tract infections, acute pyelonephritis, } \\
\text { complicated intra-abdominal infections }\end{array}$ \\
\hline Aminoglycoside & Plazomicin & Phase 3 & $\begin{array}{l}\text { Bloodstream infections and nosocomial pneumonia caused by } \\
\text { carbapenem-resistant Enterobacteriaceae }\end{array}$ \\
\hline \multirow[t]{7}{*}{ Fluoroquinolone } & WKC 771 & Phase 1 & Bacterial infections \\
\hline & WKC 2349 (WCK 771 pro-drug) & Phase 1 & Bacterial infections \\
\hline & Avarofloxacin & Phase 2 & $\begin{array}{l}\text { Community-acquired bacterial pneumonia, acute bacterial skin and } \\
\text { skin structure infections }\end{array}$ \\
\hline & Finafloxacin & Phase 2 & $\begin{array}{l}\text { Complicated urinary tract infections, acute pyelonephritis (kidney } \\
\text { infection), acute intra-abdominal infections, acute bacterial skin } \\
\text { and skin structure infections }\end{array}$ \\
\hline & Nemonoxacin & Phase 2 & $\begin{array}{l}\text { Community-acquired bacterial pneumonia, diabetic foot infection, } \\
\text { acute bacterial skin and skin structure infections }\end{array}$ \\
\hline & Zabofloxacin & Phase 2 & Community-acquired bacterial pneumonia \\
\hline & Delafloxacin & Phase 3 & $\begin{array}{l}\text { Acute bacterial skin and skin structure infections, community-acquired } \\
\text { bacterial pneumonia, uncomplicated gonorrhea }\end{array}$ \\
\hline \multirow[t]{5}{*}{ Oxazolidinone } & Tedizolid & $\begin{array}{l}\text { Approved } \\
\text { June } 2014\end{array}$ & $\begin{array}{l}\text { Acute bacterial skin and skin structure infections, hospital-acquired } \\
\text { bacterial pneumonia/ventilator acquired bacterial pneumonia }\end{array}$ \\
\hline & $\begin{array}{l}\text { Cadazolid } \\
\text { (quinolonyl-oxalidinone) }\end{array}$ & Phase 3 & Clostridium difficile-associated diarrhea \\
\hline & Radezolid & Phase 2 & $\begin{array}{l}\text { Acute bacterial skin and skin structure infections, community-acquired } \\
\text { bacterial pneumonia }\end{array}$ \\
\hline & MRX-I & Phase 1 & $\begin{array}{l}\text { Bacterial infections including community-acquired MRSA and } \\
\text { vancomycin-resistant enterococci infections }\end{array}$ \\
\hline & LCB01-0371 & Phase 1 & Bacterial infections \\
\hline Lipopeptide and glycopeptide & Oritavancin & $\begin{array}{l}\text { Approved } \\
\text { August } 2014\end{array}$ & Acute bacterial skin and skin structure infections \\
\hline \multirow[t]{2}{*}{$\begin{array}{l}\text { Glycopeptide-cephalosporin } \\
\text { heterodimer }\end{array}$} & TD-1607 & Phase 1 & $\begin{array}{l}\text { Serious Gram-positive bacterial infections (acute bacterial skin and } \\
\text { skin structure infections, hospital-acquired pneumonia/ventilator- } \\
\text { associated pneumonia, bacteremia) }\end{array}$ \\
\hline & TD-1792 & Phase 2 & $\begin{array}{l}\text { Acute bacterial skin and skin structure infections, other serious } \\
\text { infections caused by Gram-positive bacteria, including hospital- } \\
\text { acquired pneumonia/ventilator-associated pneumonia and } \\
\text { bacteremia }\end{array}$ \\
\hline \multirow[t]{2}{*}{ Lipo-glycopeptide } & Dalbavancin & $\begin{array}{l}\text { Approved } \\
\text { May } 2014\end{array}$ & Acute bacterial skin and skin structure infections \\
\hline & Ramoplanin & Phase 2 & Clostridium difficile-associated diarrhea \\
\hline Lipopeptide & Surotomycin & Phase 3 & Clostridium difficile-associated diarrhea \\
\hline
\end{tabular}


Table 2 The most important new antibiotic agents in the pipeline (Continued)

\begin{tabular}{|c|c|c|c|}
\hline \multicolumn{4}{|l|}{ Macrolide } \\
\hline Ketolide & Solithromycin & Phase 3 & $\begin{array}{l}\text { Community-acquired bacterial pneumonia, uncomplicated } \\
\text { urogenital gonorrhea }\end{array}$ \\
\hline LptD inhibitor & POL7080 & Phase 2 & $\begin{array}{l}\text { Ventilator-associated bacterial pneumonia, low respiratory } \\
\text { infections }\end{array}$ \\
\hline \multirow[t]{2}{*}{ Tetracycline } & Omadacycline & Phase 2 & $\begin{array}{l}\text { Community-acquired bacterial pneumonia, acute bacterial } \\
\text { skin and skin structure infections, complicated urinary tract } \\
\text { infections }\end{array}$ \\
\hline & Eravacycline & Phase 3 & $\begin{array}{l}\text { Complicated intra-abdominal infections, complicated urinary } \\
\text { tract infections, hospital-acquired bacterial pneumonia }\end{array}$ \\
\hline Monosulfactam & BAL30072 & Phase 1 & Multidrug-resistant Gram-negative bacterial infections \\
\hline \multirow[t]{3}{*}{ Fabl inhibitor } & Debio 1452 & Phase 2 & Acute bacterial skin and skin structure infections \\
\hline & $\begin{array}{l}\text { Debio } 1450 \text { (Debio } 1452 \\
\text { pro-drug) }\end{array}$ & Phase 1 & Bacterial infections \\
\hline & CG-400549 & Phase 2 & Acute bacterial skin and skin structure infections; osteomyelitis \\
\hline LpxC inhibitor & ACHN-975 & Phase 1 & Bacterial infections \\
\hline DNA gyrase inhibitor & AZD0914 & Phase 1 & Uncomplicated gonorrhea \\
\hline $\begin{array}{l}\text { Methionyl-tRNA synthetase } \\
\text { (MetRS) inhibitor }\end{array}$ & CRS-3123 & Phase 1 & C. difficile infection \\
\hline Peptide deformylase inhibitor & GSK-1322322 & Phase 2 & Acute bacterial skin and skin structure infections \\
\hline Type 2 topoisomerase inhibitor & GSK-2140944 & Phase 2 & $\begin{array}{l}\text { Respiratory tract infections, acute bacterial skin and skin } \\
\text { structure infections }\end{array}$ \\
\hline Bicyclolide & EDP-788 & Phase 1 & Bacterial infections \\
\hline Pleuromutilin & Lefamulin (BC-3781) & Phase 2 & $\begin{array}{l}\text { Acute bacterial skin and skin structure infections, community- } \\
\text { acquired bacterial pneumonia }\end{array}$ \\
\hline Elongation factor inhibitor & LFF571 & Phase 2 & C. difficile-associated diarrhea \\
\hline Fusidane & Taksta (fusidic acid) & Phase 2 & Prosthetic joint infections \\
\hline \multirow[t]{2}{*}{ Defensin-mimetic } & Brilacidin & Phase 2 & Acute bacterial skin and skin structure infections \\
\hline & SMT19969 & Phase 2 & C. difficile-associated diarrhea \\
\hline
\end{tabular}

Adapted from [98] with permission

of the side chain in the third position of the cephem nucleus, allowing increased antipseudomonal activity and activity against some extended spectrum $\beta$-lactamaseproducing strains. In a recent study in patients with complicated intra-abdominal infection, ceftolozane/tazobactam $(3 \times 1.5 \mathrm{~g})$ plus metronidazole was non-inferior to meropenem $(3 \times 1 \mathrm{~g})$ [102]. In another large trial, treatment with ceftolozane/tazobactam was also associated with better responses compared with high-dose levofloxacin in patients with complicated lower urinary tract infections or pyelonephritis [103].

Tedizolid is a new oxazolidinone that is more bactericidal than the currently used linezolid [104]. Although differences in clinical response rates have not been very significant, the rate of adverse events seems to be somewhat lower with tedizolid [105].

Avibactam is a new $\beta$-lactamase inhibitor active against a large number of extended spectrum $\beta$-lactamases, including class $\mathrm{A}$, some class $\mathrm{C}$, and some class $\mathrm{D} \beta$ - lactamases. It is not active against the metallo- $\beta$ lactamases, but is active against Klebsiella pneumoniae carbapenemases. Ceftazidime/avibactam combination (plus metronidazole) therapy has been tested against meropenem or imipenem in two RCTs in patients with intra-abdominal and urogenital infection. Non-inferiority of the new combination was demonstrated in both studies $[106,107]$. A study comparing ceftazidime/avibactam with meropenem in patients with nosocomial pneumonia is ongoing (ClincialTrials.gov identifier NCT01808092).

Two other new $\beta$-lactamase inhibitors are now being studied in phase III trials in patients with MDR enterobacteriaceae, including carbapenem-resistant strains. The boronate $\beta$-lactam inhibitor, RPX7007, combined with the new carbapenem, biapenem (RPX2003), demonstrated high bactericidal activity against carbapenem-resistant enterobacteriaceae [108]. MK-7655 (relebactam), in combination with imipenem/cilastatin, covers MDR enterobacteriaceae (with the exception of those producing metallo-carbapenemases), 
but in addition relebactam augments the activity of imipenem against $P$. aeruginosa in general and especially against OprD mutants of this pathogen [109].

\section{Non-antibiotic, adjunctive therapies}

We are facing increasing incidences of bacterial resistance for both community and nosocomial infections and there is a need for alternative, non-antibiotic, adjunctive therapeutic options to decrease antibiotic pressure. In the ICU, the most problematic microorganisms to treat remain $P$. aeruginosa and $S$. aureus because of their resistance profile and Clostridium difficile because of its tendency to cause relapse or recurrence.

The only effective adjunctive therapy for $C$. difficile infections appears to be toxin-neutralizing antibodies that target both toxin A and B [110]. Fecal flora reconstitution by fecal transplantation has also been shown to prevent recurrent infections for up to 1 year [111]. Moreover, $C$. difficile infection recurrence rates decreased threefold when oligofructose prebiotics or toxin-neutralizing antibodies were added to standard antibiotics. Recently, spores of $C$. difficile given by mouth were shown to be effective in stopping repeated bouts of $C$. difficile infection, which occur in $25-30 \%$ of patients who suffer an initial episode of diarrhea or colitis [112].

Monoclonal antibodies are probably the most promising adjunctive option for treating $P$. aeruginosa. Repeated doses of a monoclonal antibody targeting $P$. aeruginosa serotype $\mathrm{O} 11$ as an adjunctive therapy to antibiotics in $P$. aeruginosa hospital-acquired pneumonia and VAP were associated with a significant resolution rate without immunogenicity [113].

Human monoclonal antibodies are also being developed that specifically bind and neutralize the alpha-toxin of $S$. aureus, for adjunctive therapy in VAP. In a mouse sepsis model, treated animals had a significant reduction in mortality [114] and in a mouse pneumonia model, treatment protected against both methicillin-susceptible $S$. aureus and MRSA strains (unpublished data). Clinical trials are ongoing in patients with VAP.

Some very innovative adjunctive approaches may also be beneficial in severe infections in the ICU. Poreforming toxins (PFTs) induce lysis of host target cells by forming pores that disrupt the plasma and can cause serious complications associated with high mortality rates. About $30 \%$ of cytotoxic bacterial proteins are PFTs, making them the largest category of virulence factors. Capturing bacterial PFTs with liposomes by mimicking membrane domains thus appears a promising approach, although it is still in pre-clinical development [115].

\section{Conclusion}

Management of infection in critically ill patients is an evolving challenge, in part because of the ever-present threat of MDR strains. Alterations in PK/PD parameters in critically ill patients can complicate dosing issues, yet adequate antibiotic treatment is crucial to optimize survival rates. Therapeutic drug monitoring is likely to be more widely used in the future. Antibiotic choices and durations need to be individualized for each patient according to specific patient characteristics, disease severity, likely infecting organisms, and local resistance patterns. Although more responsible antibiotic prescribing may help reduce antibiotic pressure and development of antibiotic resistance, research needs to continue to try and identify new antibiotics and adjunctive therapies.

\section{Abbreviations}

CAP: Community-acquired pneumonia; CPIS: Clinical pulmonary infection score; CRRT: Continuous renal replacement therapy; ECMO: Extracorporeal membrane oxygenation; ICU: Intensive care unit; LBW: Lean body weight; MDR: Multi-drug resistant; MIC: Minimum inhibitory concentration; MRSA: Methicillin-resistant Staphylococcus aureus; PCR: Polymerase chain reaction; PCT: Procalcitonin; PD: Phamacodynamics; PFT: Pore-forming toxins; PK: Phamacokinetics; RCT: Randomized controlled trial; RRT: Renal replacement therapy; TBW: Total body weight; VAP: Ventilator-associated pneumonia; Vd: Volume of distribution.

\section{Competing interests}

Jean-Louis Vincent has no conflicts of interest to declare. Matteo Bassetti serves on scientific advisory boards and/or has received funding for research, travel or speaker honoraria for Bayer, Pfizer, MSD, Astellas, Basilea, Tetraphase, Gilead, Novartis, Achaogen, Paretek, Medicine Company, and Angelini. Bruno François is the coordinating principal investigator of an ongoing international phase II trial testing a monoclonal antibody against $S$. aureus to prevent VAP in ICU patients in collaboration with Medimmune, a member of the AstraZeneca group. He has no other conflicts of interest related to this manuscript. George Karam has been a consultant to, and received honoraria from, Merck and Cubist. Jean Chastre has been a consultant to and/or received honoraria from Bayer, Pfizer, Arsanis, Cubist-Merck, Kenta-Aridis, and Medimmune-AstraZeneca. Antoni Torres is on the advisory boards for Astra Zeneca, Pfizer, Bayer, and Arsanis. Jason A. Roberts is on the advisory board for Infectopharm (IV fosfomycin) and lectures for MSD (posaconazole). Fabio S. Taccone has no conflicts of interest to declare. Jordi Rello is a consultant/ member of the speakers bureau for Assign, Pfizer, Cubist, and Bayer. Thierry Calandra has received consultant income paid to his institution from Merck Sharp \& Dohme-Chibret. Daniel De Backer has no conflicts of interest to declare. Tobias Welte has received grants for research from Bayer and Novartis and fees for lectures/for advisory board membership from Bayer, Basilea, AstraZeneca, MSD, and Pfizer. Massimo Antonelli has received research grants from MSD, Pfizer, Cubist, and Toray and participated in the Advisory board for Basilea and Cubist.

\section{Authors' contributions}

Each author drafted a specific section of the manuscript and all then critically revised the whole for intellectual content. All authors read and approved the final manuscript.

\section{Acknowledgements}

Jason A. Roberts is funded by a Career Development Fellowship from the National Health and Medical Research Council of Australia (APP1048652) and would like to acknowledge funding from the National Health and Medical Research Council of Australia for a Centre for Research Excellence (APP1099452).

\section{Author details}

${ }^{1}$ Department of Intensive Care, Erasme Hospital, Université libre de Bruxelles, 1070 Brussels, Belgium. 'Infectious Diseases Division, Santa Maria Misericordia University Hospital, 33100 Udine, Italy. ${ }^{3}$ Service de Réanimation Polyvalente, CHU de Dupuytren, 87042 Limoges, France. ${ }^{4}$ Infectious Disease Section, Louisiana State University School of Medicine, 70112 New Orleans, LA, USA. ${ }^{5}$ Réanimation Médicale, Groupe Hospitalier Pitié-Salpêtrière, 75013 Paris, 
France. ${ }^{6}$ Department of Pulmonary Medicine, Hospital Clinic of Barcelona, IDIBAPS-Ciberes, 08036 Barcelona, Spain. ${ }^{7}$ Burns, Trauma and Critical Care Research Centre, The University of Queensland, Royal Brisbane and Women's Hospital, 4029 Herston, Brisbane, Australia. ${ }^{8}$ Department of Intensive care, CIBERES, Vall d'Hebron University Hospital, Universitat Autonoma de Barcelona, 08035 Barcelona, Spain. ${ }^{9}$ Infectious Diseases Service, Centre Hospitalier Universitaire Vaudois, University of Lausanne, 1011 Lausanne, Switzerland. ${ }^{10}$ Department of Intensive Care, CHIREC Hospital, Université Libre de Bruxelles, 1420 Braine L'Alleud, Belgium. ${ }^{11}$ Department of Respiratory Medicine, Medizinische Hochschule, 30625 Hannover, Germany. ${ }^{12}$ Department of Anesthesiology and Intensive Care Medicine, Catholic University of Rome, A. Gemelli University Hospital, Rome, Italy.

\section{Published online: 17 May 2016}

\section{References}

1. Ferrer R, Martin-Loeches I, Phillips G, Osborn TM, Townsend S, Dellinger RP, et al. Empiric antibiotic treatment reduces mortality in severe sepsis and septic shock from the first hour: results from a guideline-based performance improvement program. Crit Care Med. 2014;42:1749-55.

2. Pierrakos C, Vincent JL. Sepsis biomarkers: a review. Crit Care. 2010;14:R15.

3. Bauer KA, West JE, Balada-Llasat JM, Pancholi P, Stevenson KB, Goff DA. An antimicrobial stewardship program's impact with rapid polymerase chain reaction methicillin-resistant Staphylococcus aureus/S. aureus blood culture test in patients with S. aureus bacteremia. Clin Infect Dis. 2010;51:1074-80.

4. Perez KK, Olsen RJ, Musick WL, Cernoch PL, Davis JR, Land GA, et al. Integrating rapid pathogen identification and antimicrobial stewardship significantly decreases hospital costs. Arch Pathol Lab Med. 2013;137:1247-54.

5. Laffler TG, Cummins LL, McClain CM, Quinn CD, Toro MA, Carolan HE, et al. Enhanced diagnostic yields of bacteremia and candidemia in blood specimens by PCR-electrospray ionization mass spectrometry. J Clin Microbiol. 2013;51:3535-41.

6. Vincent JL, Brealey D, Libert N, Abidi NE, O'Dwyer M, Zacharowski K, et al. Rapid diagnosis of infection in the critically ill, a multicenter study of molecular detection in bloodstream infections, pneumonia, and sterile site infections. Crit Care Med. 2015;43:2283-91.

7. Cohen J, Vincent JL, Adhikari NK, Machado FR, Angus DC, Calandra T, et al. Sepsis: a roadmap for future research. Lancet Infect Dis. 2015;15:581-614.

8. Dellinger RP, Levy MM, Rhodes A, Annane D, Gerlach H, Opal SM, et al. Surviving Sepsis Campaign: international guidelines for management of severe sepsis and septic shock, 2012. Intensive Care Med. 2013;39:165-228.

9. Gordon NC, Png K, Wareham DW. Potent synergy and sustained bactericidal activity of a vancomycin-colistin combination versus multidrug-resistant strains of Acinetobacter baumannii. Antimicrob Agents Chemother. 2010;54:5316-22.

10. Wareham DW, Gordon NC, Hornsey M. In vitro activity of teicoplanin combined with colistin versus multidrug-resistant strains of Acinetobacter baumannii. J Antimicrob Chemother. 2011;66:1047-51.

11. Chandrasekar PH, Crane LR, Bailey EJ. Comparison of the activity of antibiotic combinations in vitro with clinical outcome and resistance emergence in serious infection by Pseudomonas aeruginosa in nonneutropenic patients. J Antimicrob Chemother. 1987;19:321-9.

12. Hilf M, Yu VL, Sharp J, Zuravleff JJ, Korvick JA, Muder RR. Antibiotic therapy for Pseudomonas aeruginosa bacteremia: outcome correlations in a prospective study of 200 patients. Am J Med. 1989;87:540-6.

13. Paul M, Benuri-Silbiger I, Soares-Weiser K, Leibovici L. Beta lactam monotherapy versus beta lactam-aminoglycoside combination therapy for sepsis in immunocompetent patients: systematic review and meta-analysis of randomised trials. BMJ. 2004;328:668.

14. Bliziotis IA, Samonis G, Vardakas KZ, Chrysanthopoulou S, Falagas ME. Effect of aminoglycoside and beta-lactam combination therapy versus beta-lactam monotherapy on the emergence of antimicrobial resistance: a meta-analysis of randomized, controlled trials. Clin Infect Dis. 2005;41:149-58.

15. Kumar A, Zarychanski R, Light B, Parrillo J, Maki D, Simon D, et al. Early combination antibiotic therapy yields improved survival compared with monotherapy in septic shock: a propensity-matched analysis. Crit Care Med. 2010;38:1773-85.

16. Martin-Loeches I, Lisboa T, Rodriguez A, Putensen C, Annane D, Garnacho-Montero J, et al. Combination antibiotic therapy with macrolides improves survival in intubated patients with communityacquired pneumonia. Intensive Care Med. 2010;36:612-20.
17. Postma DF, van Werkhoven $\mathrm{CH}$, van Elden LJ, Thijsen SF, Hoepelman Al, Kluytmans JA, et al. Antibiotic treatment strategies for community-acquired pneumonia in adults. N Engl J Med. 2015;372:1312-23.

18. Garin N, Genne D, Carballo S, Chuard C, Eich G, Hugli O, et al. beta-Lactam monotherapy vs beta-lactam-macrolide combination treatment in moderately severe community-acquired pneumonia: a randomized noninferiority trial. JAMA Intern Med. 2014;174:1894-901.

19. Heyland DK, Dodek P, Muscedere J, Day A, Cook D. Randomized trial of combination versus monotherapy for the empiric treatment of suspected ventilator-associated pneumonia. Crit Care Med. 2008;36:737-44.

20. Brunkhorst FM, Oppert M, Marx G, Bloos F, Ludewig K, Putensen C, et al Effect of empirical treatment with moxifloxacin and meropenem vs meropenem on sepsis-related organ dysfunction in patients with severe sepsis: a randomized trial. JAMA. 2012;307:2390-9.

21. Kumar A, Safdar N, Kethireddy S, Chateau D. A survival benefit of combination antibiotic therapy for serious infections associated with sepsis and septic shock is contingent only on the risk of death: a meta-analytic/ meta-regression study. Crit Care Med. 2010;38:1651-64.

22. Woodhead M, Blasi F, Ewig S, Garau J, Huchon G, leven M, et al. Guidelines for the management of adult lower respiratory tract infections-full version. Clin Microbiol Infect. 2011;17 Suppl 6:E1-E59.

23. Braykov NP, Morgan DJ, Schweizer ML, Uslan DZ, Kelesidis T, Weisenberg SA, et al. Assessment of empirical antibiotic therapy optimisation in six hospitals: an observational cohort study. Lancet Infect Dis. 2014;14:1220-7.

24. Lawrence $\mathrm{KL}$, Kollef $\mathrm{MH}$. Antimicrobial stewardship in the intensive care unit: advances and obstacles. Am J Respir Crit Care Med. 2009;179:434-8.

25. European Center for Disease Prevention and Control. Antimicrobial Resistance Surveillance in Europe 2013. http://ecdc.europa.eu/en/ publications/Publications/antimicrobial-resistance-surveillance-europe-2013.pdf. Accessed 29 Mar 2016.

26. Heenen S, Jacobs F, Vincent $J$ L. Antibiotic strategies in severe nosocomial sepsis: why do we not de-escalate more often? Crit Care Med. 2012;40:1404-9.

27. Garnacho-Montero J, Gutierrez-Pizarraya A, Escoresca-Ortega A, CorciaPalomo Y, Fernandez-Delgado E, Herrera-Melero I, et al. De-escalation of empirical therapy is associated with lower mortality in patients with severe sepsis and septic shock. Intensive Care Med. 2014:40:32-40.

28. Khasawneh FA, Karim A, Mahmood T, Ahmed S, Jaffri SF, Mehmood M. Safety and feasibility of antibiotic de-escalation in bacteremic pneumonia. Infect Drug Resist. 2014;7:177-82.

29. Leone M, Bechis C, Baumstarck K, Lefrant JY, Albanese J, Jaber S, et al. De-escalation versus continuation of empirical antimicrobial treatment in severe sepsis: a multicenter non-blinded randomized noninferiority trial. Intensive Care Med. 2014:40:1399-408.

30. Silva BN, Andriolo RB, Atallah AN, Salomao R. De-escalation of antimicrobial treatment for adults with sepsis, severe sepsis or septic shock. Cochrane Database Syst Rev. 2013;3, CD007934.

31. Kaki R, Elligsen M, Walker S, Simor A, Palmay L, Daneman N. Impact of antimicrobial stewardship in critical care: a systematic review. J Antimicrob Chemother. 2011:66:1223-30.

32. Davey P, Brown E, Charani E, Fenelon L, Gould IM, Holmes A, et al. Interventions to improve antibiotic prescribing practices for hospital inpatients. Cochrane Database Syst Rev. 2013;4, CD003543.

33. Solomkin JS, Mazuski JE, Bradley JS, Rodvold KA, Goldstein EJ, Baron EJ, et al Diagnosis and management of complicated intra-abdominal infection in adults and children: guidelines by the Surgical Infection Society and the Infectious Diseases Society of America. Clin Infect Dis. 2010;50:133-64.

34. Sawyer RG, Claridge JA, Nathens AB, Rotstein OD, Duane TM, Evans $H L$, et al. Trial of short-course antimicrobial therapy for intraabdominal infection. N Engl J Med. 2015;372:1996-2005.

35. Havey TC, Fowler RA, Daneman N. Duration of antibiotic therapy for bacteremia: a systematic review and meta-analysis. Crit Care. 2011;15:R267.

36. Dupuy AM, Philippart F, Pean Y, Lasocki S, Charles PE, Chalumeau M, et al. Role of biomarkers in the management of antibiotic therapy: an expert panel review: I - currently available biomarkers for clinical use in acute infections. Ann Intensive Care. 2013;3:22.

37. Shehabi Y, Sterba M, Garrett PM, Rachakonda KS, Stephens D, Harrigan P, et al. Procalcitonin algorithm in critically ill adults with undifferentiated infection or suspected sepsis. A randomized controlled trial. Am J Respir Crit Care Med. 2014;190:1102-10. 
38. Nobre V, Harbarth S, Graf JD, Rohner P, Pugin J. Use of procalcitonin to shorten antibiotic treatment duration in septic patients: a randomized trial. Am J Respir Crit Care Med. 2008;177:498-505.

39. Oliveira CF, Botoni FA, Oliveira CR, Silva CB, Pereira HA, Serufo JC, et al. Procalcitonin versus $\mathrm{C}$-reactive protein for guiding antibiotic therapy in sepsis: a randomized trial. Crit Care Med. 2013;41:2336-43.

40. Bouadma L, Luyt CE, Tubach F, Cracco C, Alvarez A, Schwebel C, et al. Use of procalcitonin to reduce patients' exposure to antibiotics in intensive care units (PRORATA trial): a multicentre randomised controlled trial. Lancet. 2010;375:463-74.

41. Joukhadar C, Frossard M, Mayer BX, Brunner M, Klein N, Siostrzonek P, et al. Impaired target site penetration of beta-lactams may account for therapeutic failure in patients with septic shock. Crit Care Med. 2001;29:385-91.

42. Felton TW, Hope WW, Roberts JA. How severe is antibiotic pharmacokinetic variability in critically ill patients and what can be done about it? Diagn Microbiol Infect Dis. 2014;79:441-7.

43. Udy AA, Roberts JA, Boots RJ, Paterson DL, Lipman J. Augmented renal clearance: implications for antibacterial dosing in the critically ill. Clin Pharmacokinet. 2010;49:1-16.

44. Udy AA, Baptista JP, Lim NL, Joynt GM, Jarrett P, Wockner L, et al. Augmented renal clearance in the ICU: results of a multicenter observational study of renal function in critically ill patients with normal plasma creatinine concentrations. Crit Care Med. 2014;42:520-7.

45. Roberts JA, Abdul-Aziz MH, Lipman J, Mouton JW, Vinks AA, Felton TW, et al. Individualised antibiotic dosing for patients who are critically ill: challenges and potential solutions. Lancet Infect Dis. 2014;14:498-509.

46. Blot SI, Pea F, Lipman J. The effect of pathophysiology on pharmacokinetics in the critically ill patient-concepts appraised by the example of antimicrobial agents. Adv Drug Deliv Rev. 2014;77:3-11.

47. Ebert SC, Craig WA. Pharmacodynamic properties of antibiotics: application to drug monitoring and dosage regimen design. Infect Control Hosp Epidemiol. 1990;11:319-26.

48. Roberts JA, Paul SK, Akova M, Bassetti M, De Waele JJ, Dimopoulos G, et al DALI: defining antibiotic levels in intensive care unit patients: are current beta-lactam antibiotic doses sufficient for critically ill patients? Clin Infect Dis. 2014;58:1072-83.

49. Taccone FS, Laterre PF, Dugernier T, Spapen $H$, Delattre I, Wittebole $X$, et al. Insufficient beta-lactam concentrations in the early phase of severe sepsis and septic shock. Crit Care. 2010;14:R126.

50. Roberts JA, Ulldemolins M, Roberts MS, McWhinney B, Ungerer J, Paterson $\mathrm{DL}$, et al. Therapeutic drug monitoring of beta-lactams in critically ill patients: proof of concept. Int J Antimicrob Agents. 2010;36:332-9.

51. Dulhunty JM, Roberts JA, Davis JS, Webb SA, Bellomo R, Gomersall C, et al. Continuous infusion of beta-lactam antibiotics in severe sepsis: a multicenter double-blind, randomized controlled trial. Clin Infect Dis. 2013;56:236-44.

52. Abdul-Aziz MH, Dulhunty JM, Bellomo R, Lipman J, Roberts JA. Continuous beta-lactam infusion in critically ill patients: the clinical evidence. Ann Intensive Care. 2012;2:37

53. Carlier M, Carrette S, Roberts JA, Stove V, Verstraete A, Hoste E, et al. Meropenem and piperacillin/tazobactam prescribing in critically ill patients: does augmented renal clearance affect pharmacokinetic/pharmacodynamic target attainment when extended infusions are used? Crit Care. 2013;17:R84.

54. Beumier M, Casu GS, Hites M, Wolff F, Cotton F, Vincent $J$, et al. Elevated beta-lactam concentrations are associated with neurological deterioration in ICU septic patients. Minerva Anestesiol. 2014;81:497-506.

55. Taccone FS, Laterre PF, Spapen H, Dugernier T, Delattre I, Layeux B, et al. Revisiting the loading dose of amikacin for patients with severe sepsis and septic shock. Crit Care. 2010;14:R53.

56. de Montmollin E, Bouadma L, Gault N, Mourvillier B, Mariotte E, Chemam S, et al. Predictors of insufficient amikacin peak concentration in critically ill patients receiving a $25 \mathrm{mg} / \mathrm{kg}$ total body weight regimen. Intensive Care Med. 2014:40:998-1005.

57. Layeux B, Taccone FS, Fagnoul D, Vincent $J$, Jacobs F. Amikacin monotherapy for sepsis caused by panresistant Pseudomonas aeruginosa. Antimicrob Agents Chemother. 2010;54:4939-41.

58. Salazar DE, Corcoran GB. Predicting creatinine clearance and renal drug clearance in obese patients from estimated fat-free body mass. Am J Med. 1988;84:1053-60.

59. Bearden DT, Rodvold KA. Dosage adjustments for antibacterials in obese patients: applying clinical pharmacokinetics. Clin Pharmacokinet. 2000;38:415-26
60. Bauer LA, Black DJ, Lill JS. Vancomycin dosing in morbidly obese patients. Eur J Clin Pharmacol. 1998;54:621-5.

61. Hites M, Taccone FS, Wolff F, Cotton F, Beumier M, De Backer D, et al. Case-control study of drug monitoring of beta-lactams in obese critically ill patients. Antimicrob Agents Chemother. 2013;57:708-15.

62. Allard S, Kinzig M, Boivin G, Sorgel F, LeBel M. Intravenous ciprofloxacin disposition in obesity. Clin Pharmacol Ther. 1993;54:368-73.

63. Pai MP, Norenberg JP, Anderson T, Goade DW, Rodvold KA, Telepak RA, et al. Influence of morbid obesity on the single-dose pharmacokinetics of daptomycin. Antimicrob Agents Chemother. 2007;51:2741-7.

64. Jamal JA, Udy AA, Lipman J, Roberts JA. The impact of variation in renal replacement therapy settings on piperacillin, meropenem, and vancomycin drug clearance in the critically ill: an analysis of published literature and dosing regimens. Crit Care Med. 2014;42:1640-50.

65. Bogard KN, Peterson NT, Plumb TJ, Erwin MW, Fuller PD, Olsen KM. Antibiotic dosing during sustained low-efficiency dialysis: special considerations in adult critically ill patients. Crit Care Med. 2011;39:560-70.

66. Pea F, Viale P, Pavan F, Furlanut M. Pharmacokinetic considerations for antimicrobial therapy in patients receiving renal replacement therapy. Clin Pharmacokinet. 2007:46:997-1038.

67. Siewert S, Drewelow B, Mueller SC. Clearance of levofloxacin by an in vitro model of continuous venovenous hemodialysis (CWHD). Int J Artif Organs. 2007:30:889-95.

68. Seyler L, Cotton F, Taccone FS, De Backer D, Macours P, Vincent JL, et al. Recommended beta-lactam regimens are inadequate in septic patients treated with continuous renal replacement therapy. Crit Care. 2011;15:R137.

69. Shekar K, Fraser JF, Smith MT, Roberts JA. Pharmacokinetic changes in patients receiving extracorporeal membrane oxygenation. J Crit Care. 2012:27:741-18.

70. Shekar K, Roberts JA, Mcdonald Cl, Fisquet S, Barnett AG, Mullany DV, et al. Sequestration of drugs in the circuit may lead to therapeutic failure during extracorporeal membrane oxygenation. Crit Care. 2012;16:R194.

71. Shekar K, Fraser JF, Taccone F, Welch S, Wallis SC, Mullany DV, et al. The combined effects of extracorporeal membrane oxygenation and renal replacement therapy on meropenem pharmacokinetics: a matched cohort study. Crit Care. 2014;18:565.

72. Ego A, Preiser JC, Vincent JL. Impact of diagnostic criteria on the incidence of ventilator-associated pneumonia. Chest. 2015;147:347-55.

73. Torres A, Ewig S. Diagnosing ventilator-associated pneumonia. N Engl J Med. 2004;350:433-5.

74. Berton DC, Kalil AC, Teixeira PJ. Quantitative versus qualitative cultures of respiratory secretions for clinical outcomes in patients with ventilatorassociated pneumonia. Cochrane Database Syst Rev. 2014;10, CD006482.

75. Shorr AF, Sherner JH, Jackson WL, Kollef MH. Invasive approaches to the diagnosis of ventilator-associated pneumonia: a meta-analysis. Crit Care Med. 2005:33:46-53.

76. Zagli G, Cozzolino M, Terreni A, Biagioli T, Caldini AL, Peris A. Diagnosis of ventilator-associated pneumonia: a pilot, exploratory analysis of a new score based on procalcitonin and chest echography. Chest. 2014;146:1578-85.

77. Nseir S, Favory R, Jozefowicz E, Decamps F, Dewavrin F, Brunin G, et al. Antimicrobial treatment for ventilator-associated tracheobronchitis: a randomized, controlled, multicenter study. Crit Care. 2008;12:R62.

78. Martin-Loeches I, Povoa P, Rodriguez A, Curcio D, Suarez D, Mira JP, et al. Incidence and prognosis of ventilator-associated tracheobronchitis (TAVeM): a multicentre, prospective, observational study. Lancet Respir Med. 2015:3:859-68.

79. Nseir S, Martin-Loeches I, Makris D, Jaillette E, Karvouniaris M, Valles J, et al. Impact of appropriate antimicrobial treatment on transition from ventilatorassociated tracheobronchitis to ventilator-associated pneumonia. Crit Care. 2014;18:R129.

80. Bouza E, Granda MJ, Hortal J, Barrio JM, Cercenado E, Munoz P. Pre-emptive broad-spectrum treatment for ventilator-associated pneumonia in high-risk patients. Intensive Care Med. 2013;39:1547-55.

81. Valles J, Peredo R, Burgueno MJ, Rodrigues de Freitas AP, Millan S, Espasa M, et al. Efficacy of single-dose antibiotic against early-onset pneumonia in comatose patients who are ventilated. Chest. 2013;143:1219-25.

82. Niederman MS, Chastre J, Corkery K, Fink JB, Luyt CE, Garcia MS. BAY41-6551 achieves bactericidal tracheal aspirate amikacin concentrations in mechanically ventilated patients with Gram-negative pneumonia. Intensive Care Med. 2012;38:263-71. 
83. Palmer LB, Smaldone GC, Chen JJ, Baram D, Duan T, Monteforte M, et al. Aerosolized antibiotics and ventilator-associated tracheobronchitis in the intensive care unit. Crit Care Med. 2008;36:2008-13.

84. Luyt CE, Eldon MA, Stass H, Gribben D, Corkery K, Chastre J. Pharmacokinetics and tolerability of amikacin administered as BAY41-6551 aerosol in mechanically ventilated patients with gram-negative pneumonia and acute renal failure. J Aerosol Med Pulm Drug Deliv. 2011;24:183-90.

85. Palmer LB, Smaldone GC. Reduction of bacterial resistance with inhaled antibiotics in the intensive care unit. Am J Respir Crit Care Med. 2014;189:1225-33.

86. Dhand R. Aerosol delivery during mechanical ventilation: from basic techniques to new devices. J Aerosol Med Pulm Drug Deliv. 2008;21:45-60.

87. Rouby JJ, Bouhemad B, Monsel A, Brisson H, Arbelot C, Lu Q. Aerosolized antibiotics for ventilator-associated pneumonia: lessons from experimental studies. Anesthesiology. 2012;117:1364-80

88. Ehrmann S, Mercier E, Vecellio L, Ternant D, Paintaud G, Dequin PF. Pharmacokinetics of high-dose nebulized amikacin in mechanically ventilated healthy subjects. Intensive Care Med. 2008;34:755-62.

89. Luyt CE, Clavel M, Guntupalli K, Johannigman J, Kennedy Jl, Wood C, et al. Pharmacokinetics and lung delivery of PDDS-aerosolized amikacin (NKTR-061) in intubated and mechanically ventilated patients with nosocomial pneumonia. Crit Care. 2009;13:R200.

90. Lu Q, Yang J, Liu Z, Gutierrez C, Aymard G, Rouby JJ. Nebulized ceftazidime and amikacin in ventilator-associated pneumonia caused by Pseudomonas aeruginosa. Am J Respir Crit Care Med. 2011;184:106-15.

91. Zampieri FG, Nassar Jr AP, Gusmao-Flores D, Taniguchi LU, Torres A, Ranzani OT. Nebulized antibiotics for ventilator-associated pneumonia: a systematic review and meta-analysis. Crit Care. 2015;19:150

92. Imberti R, Cusato M, Villani P, Carnevale L, lotti GA, Langer M, et al. Steady-state pharmacokinetics and BAL concentration of colistin in critically III patients after IV colistin methanesulfonate administration. Chest. 2010;138:1333-9.

93. Kofteridis DP, Alexopoulou C, Valachis A, Maraki S, Dimopoulou D, Georgopoulos D, et al. Aerosolized plus intravenous colistin versus intravenous colistin alone for the treatment of ventilator-associated pneumonia: a matched case-control study. Clin Infect Dis. 2010;51:1238-44.

94. Korbila IP, Michalopoulos A, Rafailidis PI, Nikita D, Samonis G, Falagas ME. Inhaled colistin as adjunctive therapy to intravenous colistin for the treatment of microbiologically documented ventilatorassociated pneumonia: a comparative cohort study. Clin Microbiol Infect. 2010;16:1230-6.

95. Tumbarello M, De Pascale G, Trecarichi EM, De Martino S, Bello G, Maviglia $R$, et al. Effect of aerosolized colistin as adjunctive treatment on the outcomes of microbiologically documented ventilator-associated pneumonia caused by colistin-only susceptible gram-negative bacteria. Chest. 2013;144:1768-75.

96. Lu Q, Luo R, Bodin L, Yang J, Zahr N, Aubry A, et al. Efficacy of high-dose nebulized colistin in ventilator-associated pneumonia caused by multidrugresistant Pseudomonas aeruginosa and Acinetobacter baumannii. Anesthesiology. 2012;117:1335-47.

97. Valachis A, Samonis G, Kofteridis DP. The role of aerosolized colistin in the treatment of ventilator-associated pneumonia: a systematic review and metaanalysis. Crit Care Med. 2015:43:527-33.

98. Bassetti M, De Waele JJ, Eggimann P, Garnacho-Montero J, Kahlmeter G, Menichetti $F$, et al. Preventive and therapeutic strategies in critically ill patients with highly resistant bacteria. Intensive Care Med. 2015;41:776-95.

99. Oldach D, Clark K, Schranz J, Das A, Craft JC, Scott D, et al. Randomized, double-blind, multicenter phase 2 study comparing the efficacy and safety of oral solithromycin (CEM-101) to those of oral levofloxacin in the treatment of patients with community-acquired bacterial pneumonia. Antimicrob Agents Chemother. 2013;57:2526-34.

100. Macone AB, Caruso BK, Leahy RG, Donatelli J, Weir S, Draper MP, et al. In vitro and in vivo antibacterial activities of omadacycline, a novel aminomethylcycline. Antimicrob Agents Chemother. 2014;58:1127-35.

101. Awad SS, Rodriguez AH, Chuang YC, Marjanek Z, Pareigis AJ, Reis G, et al. A phase 3 randomized double-blind comparison of ceftobiprole medocaril versus ceftazidime plus linezolid for the treatment of hospital-acquired pneumonia. Clin Infect Dis. 2014;59:51-61.

102. Solomkin J, Hershberger E, Miller B, Popejoy M, Friedland I, Steenbergen J, et al. Ceftolozane/tazobactam plus metronidazole for complicated intraabdominal infections in an era of multidrug resistance: Results from a randomized, double-blind, phase 3 trial (ASPECT-CIAI). Clin Infect Dis. 2015;60:1462-71.

103. Wagenlehner FM, Umeh O, Steenbergen J, Yuan G, Darouiche RO. Ceftolozane-tazobactam compared with levofloxacin in the treatment of complicated urinary-tract infections, including pyelonephritis: a randomised, double-blind, phase 3 trial (ASPECT-CUTI). Lancet. 2015;385:1949-56.

104. Prokocimer P, De Anda C, Fang E, Mehra P, Das A. Tedizolid phosphate vs linezolid for treatment of acute bacterial skin and skin structure infections: the ESTABLISH-1 randomized trial. JAMA. 2013;309:559-69.

105. Moran GJ, Fang E, Corey GR, Das AF, De Anda C, Prokocimer P. Tedizolid for 6 days versus linezolid for 10 days for acute bacterial skin and skin-structure infections (ESTABLISH-2): a randomised, double-blind, phase 3, noninferiority trial. Lancet Infect Dis. 2014;14:696-705.

106. Lucasti C, Popescu I, Ramesh MK, Lipka J, Sable C. Comparative study of the efficacy and safety of ceftazidime/avibactam plus metronidazole versus meropenem in the treatment of complicated intra-abdominal infections in hospitalized adults: results of a randomized, double-blind, Phase II trial. J Antimicrob Chemother. 2013;68:1183-92.

107. Vazquez JA, Gonzalez Patzan LD, Stricklin D, Duttaroy DD, Kreidly Z, Lipka J, et al. Efficacy and safety of ceftazidime-avibactam versus imipenemcilastatin in the treatment of complicated urinary tract infections, including acute pyelonephritis, in hospitalized adults: results of a prospective, investigator-blinded, randomized study. Curr Med Res Opin. 2012;28:1921-31.

108. Livermore DM, Mushtaq S. Activity of biapenem (RPX2003) combined with the boronate beta-lactamase inhibitor RPX7009 against carbapenemresistant Enterobacteriaceae. J Antimicrob Chemother. 2013;68:1825-31.

109. Livermore DM, Warner M, Mushtaq S. Activity of MK-7655 combined with imipenem against Enterobacteriaceae and Pseudomonas aeruginosa. J Antimicrob Chemother. 2013;68:2286-90.

110. Lowy I, Molrine DC, Leav BA, Blair BM, Baxter R, Gerding DN, et al. Treatment with monoclonal antibodies against Clostridium difficile toxins. N Engl J Med. 2010;362:197-205.

111. Guo B, Harstall C, Louie T, Veldhuyzen van Zanten S, Dieleman LA. Systematic review: faecal transplantation for the treatment of Clostridium difficile-associated disease. Aliment Pharmacol Ther. 2012;35:865-75.

112. Gerding DN, Meyer T, Lee C, Cohen SH, Murthy UK, Poirier A, et al. Administration of spores of nontoxigenic Clostridium difficile strain M3 for prevention of recurrent $C$. difficile infection: a randomized clinical trial. JAMA. 2015;313:1719-27.

113. Que YA, Lazar H, Wolff M, Francois B, Laterre PF, Mercier E, et al. Assessment of panobacumab as adjunctive immunotherapy for the treatment of nosocomial Pseudomonas aeruginosa pneumonia. Eur J Clin Microbiol Infect Dis. 2014;33:1861-7.

114. Lorenz U, Lorenz B, Schmitter T, Streker K, Erck C, Wehland J, et al. Functional antibodies targeting IsaA of Staphylococcus aureus augment host immune response and open new perspectives for antibacterial therapy. Antimicrob Agents Chemother. 2011;55:165-73.

115. Henry BD, Neill DR, Becker KA, Gore S, Bricio-Moreno L, Ziobro R, et al. Engineered liposomes sequester bacterial exotoxins and protect from severe invasive infections in mice. Nat Biotechnol. 2015;33:81-8.

116. Chiurazzi C, Motos-Galera A, Torres A. Early identification of ventilatorassociated pneumonia causative pathogens: focus on the value of Gram-stain examination. In: Vincent $J \mathrm{~L}$, editor. Annual update in intensive care and emergency medicine. Heidelberg: Springer; 2015. p. 3-14. 